\title{
Mathematicians as Great Economists: John Forbes Nash, Jr.
}

\author{
Matthew J. Ryan
}

$\mathrm{S}^{\prime}$ ylvia Nasar's recent book, A Beautiful Mind, and a film of the same title about the life of John Nash have piqued public curiosity about this most interesting of characters. However, an important aspect to Nash's story is neglected by these sources. This is the tale of the rise and fall, and rising again, of his ideas, and their ultimately enormous influence on social science. Economic and political theory are now heavily based upon the 'rational strategic' models of human behaviour that Nash pioneered. The impact of this new theory on policy is also apparent. It has altered the conduct of monetary policy and the relationship between central bankers and elected public representatives; utterly transformed the work of the ACCC and other regulatory bodies; informed decisions about whether and how to auction public assets; and revised thinking on the negotiation of international trade and other agreements.

What follows is a selective and, more importantly, an interpreted history of why and when the influence of Nash's ideas came to be so strongly felt, particularly within economics. I hope that the history is accurate; but the interpretation is of course subjective, and proffered as a stimulus to further debate.

The nub of the debate is, I believe - what makes a mathematician a great economist? As is well known, Nash is a mathematician, and attended but a single course in economics - undergraduate International Trade at Carnegie Tech (now Carnegie Mellon University). The work by which he is best known to economists is contained in three papers - a mere 30 pages - published between 1950 and 1953: Nash $(1950 b ; 1951 ; 1953)$. Indeed, his Nobel citation refers primarily to the second of these, which contains the substance of Nash's PhD thesis. After 1953, Nash's attention turned to mathematical problems of no obvious interest to economists.

Why should a mathematician, with such a paucity of direct involvement in the enterprise of economics research, have been bestowed (albeit amid unprecedented controversy) with two of economics' highest honours: the Nobel Prize (1994) and fellowship of the Econometric Society (1990)? The case of Nash's PhD supervisor, Albert Tucker, provides a useful comparison. In 1951, the very same year in which Nash's Nobel Prize-winning paper appeared, Tucker and his co-author, Harold Kuhn, published a famous paper on the mathematics of optimisation. The 'Kuhn-Tucker Theorem' now appears routinely in economics textbooks, and is known to virtually every graduate student of the subject. But Kuhn and Tucker are no more regarded as part of the economics Pantheon than are

Matthew Ryan is a Lecturer and ARC Senior Research Associate in the School of Economics at the Australian National University. 
the inventers of calculus. Just because economists use mathematics, this does not make mathematicians famous contributors to economics. Why has John Nash been singled out?

To understand the answer, we must relate the tale of the turbulent relationship between mathematics and economics. Let us begin by describing the intellectual landscape into which Nash first makes his appearance.

\section{Setting the Scene}

The year 1948, in which John Nash entered Princeton as a new PhD student, saw the confluence of two powerful forces that would have a lasting impact on economic research. The first was the increasing acceptance of mathematical formalism in economic analysis, culminating in the publication of Paul Samuelson's Foundations of Economic Analysis in 1947.

The second was the emergence of a new field of mathematics, called game theory. John von Neumann's and Oskar Morgenstern's Theory of Games and Economic Behavior was the first substantive treatise in this new field. Its first edition appeared in 1944, and an important second edition - the first to include the famous expected utility model - in 1947.

As the title of von Neumann's and Morgenstern's book suggests, and its first chapter puts beyond doubt, the authors were convinced that game theory held significant promise as a tool for mathematical economic research. The rapid convergence of these two streams of intellectual development therefore seemed imminent.

\section{Mathematical economics and the 'neoclassical' agenda}

The first major economic treatise to make substantial use of mathematics - that is to say, elementary calculus and algebra - was the Recherches sur les Principes Mathematiques de la Theorie des Richesses (1838) by Antoine Augustin Cournot. This was, at the time, a rather radical departure from the norm, and the book was not well received, prompting Cournot to publish a non-mathematical version, the Principes de la Theorie des Richesses, in 1863. Far from being lauded for introducing new discipline and rigour into academic discourse on political economy, the mathematical method was scorned as irrelevant window-dressing, or worse, as a deluded subversion of social science.

However, by the late 19th century, the tide was beginning to turn. The impressive work of Jevons, Walras, Edgeworth, Pareto, Marshall and others slowly won over the nay-sayers. Acceptance of the utility of mathematical analysis spread amongst the agenda-setters of the discipline. As Irving Fisher (1898:136) observed in reviewing the 1897 English translation of Cournot's Principes Mathematiques:

Marshall's diagrams and formulae were called dangerous, falsely accurate, academic playthings. ... To-day few economists can be found 
who regard diagrams as useless curiosities or as waste of valuable page space.

It should be noted that diagrams of this sort are now used to teach first-year undergraduates! The cogniscenti of 1898 may indeed have embraced the mathematical method, but the level of technical analysis was rather low.

The next milestone in the progress of mathematical economics was Samuelson's Foundations, which 'actively contributed to raising the level of analysis in economic science'. So reads Samuelson's 1970 Nobel Prize citation. Samuelson (http://www.nobel.se/economics/laureates/1970/samuelson-bio.html) himself put it more pithily, claiming his mathematics saved economists from practising 'mental gymnastics of a peculiarly depraved type'. His Foundations also brought the new mathematical approach to the rank-and-file of graduate students, academics and other practising economists.

However, it is inevitable that the desire to impose the discipline of mathematical formalisation on economics should entail a narrowing of the research agenda. Some topics were better suited than others to expression in precise mathematical terms.

As an example, suppose that one is interested - as economists are - in understanding the functioning of competitive markets. A natural starting place for the analysis is a bargain struck between two traders. However, pre-War economists had virtually given up hope of formalising the process by which bargaining determines the division of surplus; that is, price. This is vividly expressed in the exasperated words of Edgeworth (1881:46): the division, he declared, must necessarily be determined by 'higgling dodges and designing obstinacy, and other incalculable and often disreputable accidents.'

Sadly, the analysis of 'higgling dodges' continues to elude adequate formalisation. What are we to do? If one cannot predict the outcome of individual bargains, how are we to understand complex interacting markets with thousands of traders? Fortunately, the study of markets 'in the large' turns out to be easier than that of bargaining 'in the small'. By studying dense markets, with many buyers and many sellers, individual negotiation skills become irrelevant. A 'market price' asserts itself inexorably upon the process of trading.

In these densely populated markets, traders cease to eyeball each other across the negotiating table, and instead operate anonymously, consulting a price posted by the 'invisible hand' of market forces, and submitting their trades to a central clearing house. This is the paradigm of the so-called Walrasian market, which quickly came to dominate economic theorising.

All direct human interaction is mired in the vagaries of human psychology and emotion. Resorting to the idealisation of homo rationalis does little to improve matters. In an interactive social environment, one's own best course of action can be determined only once one has formed a belief about how others will act. Since these 'others' face a symmetric decision problem, an impasse is reached. Like the bargaining problem, many avenues of obvious economic enquiry were blocked in this manner. With face-to-face human interaction 
effectively off the agenda, economics had thus become a rather 'asocial' branch of social science.

\section{Game theory}

Game theory is the mathematical analysis of precisely these sorts of human interactions. It is the science of strategic decision-making. In the abstract, a strategic decision may be defined as one whose consequences are not uniquely determined by the decision-maker's own actions plus exogenous random forces ('chance'), but are also affected by the deliberate actions of other people. Such problems are fundamental to any social science.

As its name suggests, the origins of game theory may be found in attempts to devise winning strategies in popular parlour games, such as chess, poker and 'paper, rock, scissors'. Important contributions to statistics and probability arose from the study of 'games of chance'; and so too did these apparently frivolous musings upon 'games of strategy' lead ultimately to powerful insights into such weighty matters as military tactics, oligopolistic behaviour, evolutionary biology, and politics.

Game theory existed as a branch of mathematics before Nash began writing on the subject, but only just. The French mathematician Emile Borel and the Hungarian wunderkind John von Neumann had written a few papers on the subject in the 1920s, and there were some other early contributors of lesser significance. The key result to emerge from this early literature was von Neumann's famous Minimax Theorem (1928).

This theorem provided a solution to so-called two-player, zero-sum games. In such games, player payoffs always sum to zero: the winnings of one player must be exactly matched by the losses of the other. The Minimax Theorem suggested an optimal way to play such games.

As a simple example, consider the game of Matching Pennies. The players are designated One and Two, and each player places a penny on the ground simultaneously. If both match (that is, both pennies are 'heads' up, or both are 'tails' up), Player One keeps both pennies; otherwise both pennies go to Player Two. This is a zero-sum contest, since one player must gain a penny and the other must lose one. The game is illustrated schematically below. The payoffs to any given strategy pair is indicated in the corresponding cell of the matrix, with Player One's payoff listed first.

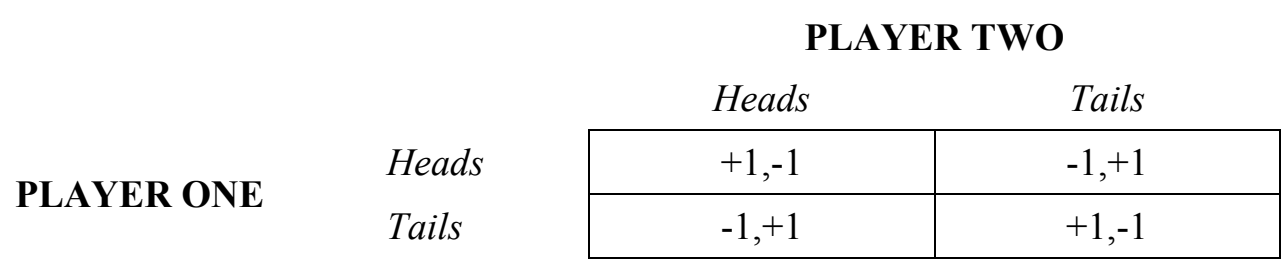

Because each player's attempt to maximise her own position in a zero-sum contest is simultaneously an attempt to inflict maximal damage upon the other, it 
is natural to consider the worst-case scenario associated with each strategy (that is, the scenario in which the rival's strategy inflicts the minimal payoff). For any given strategy, its worst-case scenario payoff is called its security level. A maximin strategy is one that maximises the player's security level. This is an obvious 'defensive' strategy in such games.

Interestingly, as von Neumann and others had recognised, a maximin strategy may require the player to randomise. The maximin strategy for a player in Matching Pennies, for example, is to toss the penny, rather than place it. This gives a 0.5 probability of 'winning' no matter what the other player does. Hence, the tossing strategy guarantees a payoff of zero (in expected value). Any other strategy, randomised or otherwise, has a security level that is strictly less than zero. (When players toss their coins, Australian readers may recognise Matching Pennies as a simple version of Two Up.)

The Minimax Theorem demonstrates that if one player adopts a maximin strategy, then the other can do no better than to do likewise. Therefore, maximin strategies are mutual 'best responses'. They are in a relationship of equilibrium with respect to each other.

It therefore seems compelling that the best advice to give a player in a twoperson, zero-sum contest is to play a maximin strategy. Importantly, while players in some games may have many different maximin strategies, the Minimax Theorem implies that it doesn't matter which is chosen. Each can be expected to perform as well as the other(s). This is sometimes expressed by saying that the strategies are interchangeable.

In 1944, with the publication of von Neumann's and Oskar Morgenstern's Theory of Games and Economic Behavior (henceforth TGEB), the scattered contributions to game theory were synthesised and extended. It also set an agenda that took considerable hold of the discipline for years to come.

For our purposes, two features of this book are noteworthy. First, it contains essentially no new important game-theoretic results. Its theoretical centrepiece remains the Minimax Theorem. In particular, the authors' analysis of non-zerosum games, and games with more than two players, produced a lot of interesting ideas, but no firm conclusions. A 'solution' for such games remained elusive.

Second, Morgenstern, an economist at Princeton, had perceived the potential value of game theory to economics, and convinced von Neumann to pitch the book in this direction. Indeed, TGEB was very favourably reviewed by leading economic theorists such as Leonid Hurwicz (1945), Jacob Marschak (1946) and Richard Stone (1948).

Unfortunately, most economic problems are not zero-sum in nature. For example, the bargaining problem involves the potential for mutual advantage through trade, and with respect to bargaining, TGEB was unable to improve on the dispiriting conclusion of Edgeworth. Morgenstern was aware of this imperfect match between the tools that TGEB was able to provide and the needs of economists. Nevertheless, in the section on 'Necessary Limitations of the Objectives' he recalls from the history of the physical sciences that 'in the study of problems which were modest as compared with the ultimate aims, methods were 
developed which could be extended further and further' (von Neumann and Morgenstern (1947:6)).

And so, the stage is set ...

The year 1948 dawns, and Mr Nash goes to Princeton, the birthplace of TGEB. Economists are increasingly receptive to sophisticated mathematical ideas, and Morgenstern has alerted them to the potential value of game theory.

By the time Nash has completed his $\mathrm{PhD}$ in 1950, he will have provided precisely the extensions to TGEB that economists sought, including a solution to the famous bargaining problem. All seems in readiness, then, for economics to embrace game theory. Instead, the basic ideas of game theory and its powerful applications to economics were largely ignored for the next twenty-five years.

\section{Two Important Results of John Nash}

Let us first examine Nash's two key contributions - Nash equilibrium and the Nash bargaining solution - in more detail. The first of these is a contribution to the theory of non-cooperative games: those in which the players are unable to write enforceable contracts. The bargaining problem, by contrast, is a cooperative game, since the bargain may be written down and enforced through an external mechanism (that is, the courts). Indeed, this important distinction between cooperative and non-cooperative games is another of Nash's contributions.

\section{Nash equilibrium}

Recall that the appeal of the maximin solution to zero-sum games arises from two features: maximin strategies offer a natural defensive posture; and a situation of 'equilibrium' results when players adopt such strategies. Nash observed that the first property does not survive outside the zero-sum context, but showed that the second alone is sufficient to extend the solution beyond it. A Nash (1950a; 1951) equilibrium is a collection of strategies - one for each player - that are mutual best responses. For zero-sum games, only maximin strategies may be played in a Nash equilibrium, but Nash proved that equilibrium strategies exist for any noncooperative game, including games that are not zero-sum, and those with more than two players. This is Nash's famous equilibrium existence result.

Nash equilibrium also conveyed a powerful contrarian message to economists enamoured of the efficiency of Walrasian markets. Consider the following example, cited in Milnor (1995). Some readers may recognise it as a variation on the classic Prisoners' Dilemma game, which is attributed to Albert Tucker but first appeared in print in Nash (1951).

A group of 20 people is going to dinner, and each must choose between a $\$ 10$ meal and a $\$ 20$ meal. Each values the expensive meal only $\$ 5$ more than the cheaper one, so if each pays individually, all diners choose 
the $\$ 10$ meal. But if the bill is split, the meal choice becomes a strategic problem, and the only Nash equilibrium is for each to choose the $\$ 20$ meal: any individual who opted for the $\$ 10$ meal would forego $\$ 5$ worth of additional value which they might have secured for only 50 cents.

When the bill is split, each diner obtains some 'market power' over the 'price' paid by the other diners for their meals. The individually rational exercise of this market power leads to a socially inefficient outcome. Everyone is made worse off.

Of course, economists in 1950 were already aware of the efficiency problems with imperfectly competitive markets, but Nash's equilibrium provided a powerful unifying principle with which to understand and generalise these phenomena.

\section{The Nash bargaining solution}

In bargaining problems, it is assumed that the capacity to sign binding contracts eliminates efficiency problems. If an enforcement mechanism were available, Milnor's diners would readily have signed contracts committing themselves to the cheaper meal, whether or not the bill was to be split. In bargaining, the problem is not to ensure that maximal surplus is achieved, but to determine how it will be shared.

Abstractly conceived, a two-person bargaining problem consists of a set of feasible contracts, with associated payoffs to each bargainer. As Edgeworth, von Neumann and Morgenstern, and others had observed, it is reasonable to suppose that the chosen contract will satisfy:

- Efficiency: No other feasible contract offers both bargainers a higher payoff.

However, this requirement typically leaves a large number of possibilities. Choice amongst them, it was felt, could only be determined by understanding the complex psychology of bargaining. Nash $(1950 \mathrm{~b} ; 1953)$ demurred. The process by which the ultimate bargain is negotiated may be complex, he agreed, but elementary principles of rationality dictate some additional properties of its outcome.

- Symmetry: If the bargaining problem is symmetric (that is, if for every feasible contract, there exists another which swaps the bargainers' payoffs), then the chosen contract should award each bargainer the same payoff.

- Independence of Irrelevant Alternatives: If bargaining reaches a particular outcome, and we discard some of the unused contracts and ask the parties to renegotiate over the smaller set of contracts, they should opt for the same outcome as before.

While these principles are not without their critics, particularly the latter, the remarkable thing is that they should be sufficient to determine a unique outcome 
to any bargaining problem. Using an argument of almost magical simplicity, Nash showed that these three principles can only be satisfied if the bargainers choose the contract that maximises the product of their payoffs. The bargaining problem had been brilliantly solved.

\section{Denouement delayed}

Precisely why Nash's results failed to ignite the ardour of economists at the time remains unclear. However, at least two factors appear to have been important.

First, mathematicians held the 'line' of TGEB, and rejected Nash's equilibrium as an inadequate solution for general non-cooperative games. This bad press from the mathematics community, and the consequent absence of mathematicians actively developing Nash's ideas, must certainly have been discouraging to potential end-users.

Second, economists proved reluctant to expand their horizons beyond the entrenched neoclassical agenda. Appropriate new questions simply did not get asked. To the extent that game-theoretic ideas infiltrated economics, they were the ideas that economists found useful in understanding Walrasian markets.

\section{The normative agenda in game theory}

When Nash described his equilibrium existence result to von Neumann, the latter cut Nash's explanation short with the dismissive words (Nasar, 1998:94): 'That's trivial, you know. That's just a fixed point theorem.'

Other mathematicians working on game theory were similarly unimpressed by Nash's ideas. This is evident in the influential Games and Decisions by R. Duncan Luce and Howard Raiffa (1957) - a highly successful attempt to make game theory accessible to a wider audience of social scientists. After reviewing some of its properties, Luce and Raiffa (p. 104) find Nash equilibrium wanting, and conclude that 'a unified theory for all possible non-cooperative non-zero-sum games does not seem possible'.

This judgement sounds almost shocking to modern ears. Nash equilibrium is now accepted without question as the way to 'solve' games. Why did mathematicians reject it?

Let us examine von Neumann's charge of 'triviality' first. With minimal reading between the lines of history, it is entirely plausible that von Neumann was either aware of the possibility of proving Nash's result, or capable of reaching such a conclusion within a few short logical steps. The logic of equilibrium was familiar to him from his zero-sum analysis, as we have already observed. Moreover, he was also familiar with the basic mathematical tool - fixed point theory - that Nash used to extend this equilibrium logic to general noncooperative games. Indeed, for a paper on economic growth written in 1932 von Neumann's one other foray into economics - von Neumann (1945-6) proved a fixed point theorem essentially equivalent to the one applied in Nash (1950a), an 
early version of Nash's equilibrium existence result ${ }^{1}$. In his growth paper, von Neumann (1945-46:5.) even observes that the Minimax Theorem follows as a direct corollary of this fixed point theorem. Thus, von Neumann was aware of the logic of equilibrium, acquainted with fixed point theory, and aware of the utility of the latter in connection with the former. Nash's result was surely within his grasp.

It is not surprising, therefore, that von Neumann saw Nash's result before Nash had finished his explanation, and saw little novelty in it. One is therefore lead to the question: Why had von Neumann not already written down the extension of equilibrium to general non-cooperative games? The answer is evident in the lukewarm reception to the idea expressed by Luce, Raiffa and others in the game theory community. Game theorists simply did not think Nash equilibrium a viable 'solution' to non-zero-sum games. They felt it to be conceptually flawed.

The reason for this, it seems clear, was the normative orientation of mathematical game theory. True to its origins, game theory in the 1950s still sought to advise players on how best to make their strategic decisions. Nash equilibrium failed to generate unambiguous advice, since many non-zero-sum games possess a multiplicity of equilibria that are not interchangeable. The best advice to give one player depends upon the advice being received by the other, even if both are being advised according to Nash's theory, and so we arrive at yet another strategic impasse.

Social scientists, of course, are not concerned to advise people how the ought to behave, but rather to understand how they do behave. They required a positive theory of games. Nash equilibrium served this descriptive purpose perfectly. Indeed, even Luce and Raiffa (1957:105) tempered their criticism of Nash with the observation that:

Even if we were to reject equilibrium as a normative theory for noncooperative games ... it may still be that the notion is relevant as a description of behavior.

What evidence is there that Nash interpreted his own work in a positive spirit? On the one hand, his 1951 paper reserves the term 'solution' for cases in which a game's Nash equilibria are interchangeable. This suggests a normative inclination. However, one may also argue that Nash was merely adopted a usage of the term 'solution' that was consistent with its normative origins in the earlier work on zero-sum games. In other words, he may have seen his equilibrium as a satisfying descriptive analysis for all games, but an adequate normative solution only for games in which the additional requirement of interchangeability is satisfied.

Indeed, there is compelling evidence elsewhere that Nash did seek to motivate his equilibrium as a positive concept. Much of this evidence was

1 von Neumann (1945-6) is an English translation of von Neumann's paper, originally published in German in 1938. 
obscured from public view because of the omission of a section on 'Motivation and Interpretation' from the published version of Nash's PhD thesis. In this section, Nash (cited in van Damme and Weibull (1995, p.19, emphasis added)) says that he wishes to answer the question: '(W)hat would be a rational prediction of the behavior to be expected of rational players in the game in question?'.

He also goes on to propose what he calls a 'mass action' interpretation of equilibrium. He suggests that equilibria may come to be played through an evolutionary process by which a population of players are randomly matched and re-matched in the same contest. Their strategy choices evolve, and will only stop evolving once an equilibrium has been reached, so that no deviating 'mutant' can obtain a superior outcome. This interpretation was independently re-invented in the 1970s, and evolutionary game theory is now a thriving branch of the discipline.

In the 'mass action' story, the strategies of all players evolve together. There is no need of interchangeability, since strategies are jointly determined. If multiple equilibria exist, this only reflects the inability of Nash's logic to generate unique predictions. The players themselves know perfectly well which equilibrium they are playing; only we, as outside observers, are in doubt.

One also sees a methodological unity between Nash equilibrium, under the 'mass action' interpretation, and his bargaining solution. In both cases, Nash uses elementary principles to narrow down the plausible outcomes of an underlying process of considerable complexity. This methodology is now unquestioningly accepted and powerfully applied by economists and other social scientists. However, it was certainly not embraced immediately.

\section{The apotheosis of Walrasian market theory}

Why it was not so embraced remains an intriguing unsolved mystery. Certainly, leading economists had more than enough mathematical facility to read and interpret Nash for themselves. Indeed, Nash's papers were read, and their ideas syphoned off by economists. However, in one of the great ironies of our story, the ideas were applied to understand the non-strategic behaviour of Walrasian markets, not strategic interaction.

Kenneth Arrow and Gerard Debreu were directly inspired by Nash's fixedpoint arguments (Debreu, 1952 $2^{2}$; Arrow and Debreu, 1954). By adapting these arguments, they were able to show that, under fairly weak assumptions, there will always exist a set of prices that balance supply and demand simultaneously on a system of Walrasian markets. This is known as a Walrasian equilibrium.

Even the Minimax Theorem exerted an indirect influence on economic theory at this time. Tjalling Koopman's activity analysis, for which he won a Nobel Prize in 1975, is an application of duality theory in linear programming, which is

2 Interestingly, Debreu's paper was communicated to the National Academy by John von Neumann. 
itself a corollary of the Minimax Theorem. Economists were not only out of practice at asking the sorts of questions that game-theoretic tools were useful in answering, the usefulness of the mathematics of games to the neoclassical agenda contributed to the temporary demise of game theory itself within economics. Indeed, this traditional agenda acquired a new momentum that sustained it into the 1970s.

\section{The Game-theoretic Revolution}

As Aumann (1985:43) states:

The Nash equilibrium is the embodiment of the idea that economic agents are rational; that they simultaneously act to maximise their utility. If there is any idea that can be considered the driving force of economic theory, that is it.

By the mid-1970s economics was ready for a new paradigm. The heyday of research into Walrasian markets was over, and graduate students were looking for new topics on which to write their dissertations. A game-theoretic revolution in economics was about to take place.

Of course, economists had never entirely abandoned game theory, or Nash's ideas. Both had persisted at the fringes of the discipline, sustained by the work of theorists such as Robert Aumann, John Harsanyi, Lloyd Shapley and Martin Shubik. It is also true, as I have attempted to convey, that the ideas of Nash were so compellingly useful to economists, that it was only ever a question of 'when' they would be adopted, not 'if'. Nevertheless, an explanation is required for their suddenly being thrust centre stage at this particular juncture.

Definitive answers are elusive, but some influential factors are evident. The first is the aforementioned loss of steam from the research program into Walrasian markets. Second, political scientists have suggested that game theory may have re-entered economics via politics, where it had spawned the important new 'positive political theory' school, lead by William Riker, in the 1960s (Amadae and Bueno de Mesquita, 1999). Indeed, the use of game theory in political science has seen a growing together of economics and politics. A new political economy, formalised along game-theoretic lines, has emerged. Theories of voting, lobbying and other political phenomena are now routinely taught in economics programmes.

Finally, there was the important catalyst provided by Nash's two Nobel colaureates: Reinhard Selten and John Harsanyi. Selten pioneered the literature on so-called refinements of Nash equilibrium. By tightening the predictive power of equilibrium, the refined solutions greatly enhanced the attractiveness of game theoretic tools for applied work. Harsanyi enhanced Nash equilibrium in the opposite direction, by expanding its scope of application. Nash, like the game theorists before him, had assumed that all players knew the payoff consequences for all rivals of any given outcome of the game. This complete information assumption is frequently unrealistic. For example, in the context of an auction, it 
requires that each bidder know every other bidder's valuation of the object for sale. Harsanyi indicated how the complete information assumption might be dispensed with using an elaboration of the Nash logic known as a Bayesian Nash equilibrium. A vast new array of interesting problems could now be successfully tackled.

With respect to the contributions of Selten and Harsanyi, however, let me not give the false impression that Nash's ideas were inadequate in their own right. It was not that Selten's and Harsanyi's embellishments were necessary to make Nash equilibrium serviceable. The new ideas re-ignited interest in game theory, but they did not render Nash equilibrium obsolete. On the contrary, as Aumann (1985:48) observes: 'Nash equilibrium is without doubt the most 'successful' that is, widely used and applied - solution concept in game theory.' Indeed, most applied work on problems of complete information employ nothing more than simple versions of the Selten refinement that combine Nash equilibrium with the even older idea of 'backward induction'. This combination is already evident in Nash's own work: see Nash (1953).

\section{Game Theory and the Modern Agenda in Economics}

To conclude, let me return to the question: what distinguishes the contributions of Nash from those of his supervisor, Tucker? Unlike any other single idea, Nash equilibrium has transformed the agenda in economics, and in social science more broadly. While the Kuhn-Tucker Theorem allowed economists to do what they had already been doing more effectively, Nash's equilibrium opened entirely new avenues of research, and substantially altered both the scope and the focus of economics. In particular, the credit for this must go to Nash himself, rather than to the collective enterprise of game theory. Nash was the first to see clearly how game theory might be used in a positive mode, and is one of its most accomplished exponents. Reading the game theory literature of the 1950s, it is striking how Nash stands out as the most 'modern', the most in tune with contemporary thinking about strategic analysis in social science. This is indeed no accident.

It scarcely needs to be emphasised that game theory is now ubiquitous within economic research, from industrial organisation, whose existence one could scarcely imagine without it, to strategic trade theory, law and economics, and even macroeconomics. Indeed, game theory itself now exists as a field within economics, entirely separate from the kindred branch of mathematics.

The analysis of markets now focuses heavily on the 'visible hand' of the strangely mis-named 'imperfect competition', rather than the 'invisible hand' of the shadowy Walrasian mechanism. To the extent that Walrasian markets are the object of continued theoretical interest, this is directed at providing strategic foundations in terms of individual bargaining. Nash's bargaining solution is the key ingredient in this endeavour.

Most importantly, perhaps, is the way in which game theory has transformed the 'dismal science' into a truly 'social' science, and reconnected it with its 
brethren: political theory, sociology, law, anthropology, and even biology. Social and economic institutions are now viewed as mechanisms that determine the rules of the games that people play. Normative questions of institutional design (socalled mechanism design or implementation theory) may be addressed in an intellectually satisfying manner. Dialogue on these issues of common interest is now possible between economists, political scientists and other social philosophers. This, ultimately, may be the most significant legacy of Nash (Myerson, 1996:273-4):

Methodological limitations no longer deter us from recognising the essential interconnections between economic, social, and political institutions in economic development. ... Today, the original scope of political economy has been restored to economic theorists, because of the general methodology that John Nash introduced.

\section{References}

Amadae, S. and B. Bueno de Mesquita (1999), 'The Rochester School: The Origins of Positive Political Economy’, Annual Review of Political Science 2:269-295.

Arrow, K. and G. Debreu (1954), 'Existence of Equilibrium for a Competitive Economy', Econometrica 22:265-290.

Aumann, R. (1985), 'What is Game Theory Trying to Accomplish?', pp. 28-76 in K. Arrow and S. Honkapohja (eds), Frontiers of Economics, Basil Blackwell, Oxford.

Debreu, G. (1952), 'A Social Equilibrium Existence Theorem', Proceedings of the National Academy of Sciences of the U.S.A., 38:886-893.

Cournot, A. (1987), Researches into the Mathematical Principles of the Theory of Wealth, MacMillan, New York. (English translation by N. Bacon of Cournot's original French publication of 1838).

van Damme, E. and J. Weibull (1995), 'Equilibrium in Strategic Interaction: The Contributions of John C.Harsanyi, John F. Nash and Reinhard Selten', Scandinavian Journal of Economics 97(1):15-40.

Edgeworth, F. (1881), Mathematical Psychics, C. Kegan Paul and Co. London.

Fisher, I. (1898), 'Cournot and Mathemtical Economics', Quarterly Journal of Economics 12(2):119-138.

Hurwicz, L. (1945), 'The Theory of Economic Behavior', American Economic Review 35(5):909-925.

Luce, R. and H. Raiffa (1957), Games and Decisions, John Wiley and Sons, New York.

Marschak, J. (1946), 'Neumann's and Morgenstern's New Approach to Static Economics', Journal of Political Economy 54(2):97-115. 
Milnor, J. (1995), 'A Nobel Prize for John Nash', The Mathematical Intelligencer 17(3):11-17.

Myerson, R. (1996), 'John Nash's Contributions to Economics', Games and Economic Behavior 14:287-295.

Nasar, S. (1998), A Beautiful Mind, Faber and Faber, London

Nash, Jr., J. (1950a), 'Equilibrium Points in N-Person Games', Proceedings of the National Academy of Sciences of the U.S.A. 36:48-49.

Nash, Jr., J. (1950b), ‘The Bargaining Problem', Econometrica 18:155-162.

Nash, Jr., J. (1951), 'Non-Cooperative Games', Annals of Mathematics 54(2):286-295.

Nash, Jr., J. (1953), ‘Two-Person Cooperative Games', Econometrica 21:128-140.

von Neumann, J. (1945-6), ‘A Model of General Economic Equilibrium', Review of Economic Studies 13:1-9.

von Neumann, J. and O. Morgenstern (1947), The Theory of Games and Economic Behavior, 2nd edition, Princeton University Press, Princeton, NJ.

Samuelson, P. (1947), Foundations of Economic Analysis, Harvard University Press, Cambridge, MA.

Stone, R. (1948), ‘The Theory of Games', Economic Journal 58:185-201.

This paper is based on a Toyota/ANU Public Lecture, 21 March 2002. My thanks to the School of Mathematical Sciences at the ANU for inviting me to write and speak on this topic. Thanks also to Gerry Mackie, Guillaume Rocheteau, two anonymous referees, and seminar participants in the School of Economics at the $A N U$, for helpful comments on an earlier draft. 